\title{
Relation between Increases in Stomatal Conductance of Decorative Sepals and the Quality of Antique-stage Cut Hydrangea Flowers
}

\author{
Yoshikuni Kitamura*, Yukari Kato, Toshiki Yasui, Hiroe Aizawa and Sachiyo Ueno \\ Faculty of Agriculture, Shinshu University, Minamiminowa, Nagano 399-4598, Japan
}

Cut hydrangea (Hydrangea spp.) flowers are marketed at two different harvest stages, the fresh- and antiquestages. Flowers cut at the fresh-stage are harvested just after the coloring of decorative sepals is completed before flowering, and flowers cut at the antique-stage are harvested when the decorative sepals develop green and/or red colors after flowering. In almost all cultivars, an increase in the hydraulic conductance of the stomata (stomatal conductance) of the abaxial side of decorative sepals occurs during the transition from the fresh to the antique-stage. We investigated the relation between the stomatal conductance increase and the severity of the damage to decorative sepals. The degree of stomatal conductance increase regressed with the severity of the damage occurrence to the antique-stage decorative sepals before harvest. The relation between the stomatal conductance increase and vase life of antique-stage cut hydrangea flowers was also investigated. Abscisic acid (ABA)-treated antique-stage cut flowers exhibited lower stomatal conductance on the abaxial side of decorative sepals than control cut flowers. A photoperiodic change in the transpiration was observed in the control cut flowers, but not in ABA-treated cut flowers. These ABA treated cut flowers had longer vase lives than control cut flowers. To achieve minimal damage before harvest and longer vase life in the antiquestage during cut hydrangea flower production, screening for stomatal conductance non-increasing cultivars would be desirable. Since the stomatal conductance of antique-stage decorative sepals showed a highly significant correlation with fresh-stage decorative sepals, these can be used as an index in screening for stomatal conductance non-increasing cultivars.

Key Words: abscisic acid, functional stomata, sepal damage, transpiration, vase life.

\section{Introduction}

In Japan, the consumption of cut hydrangea (Hydrangea spp.) flowers has increased in recent years. Inflorescences of hydrangea are classified into two types according to the arrangement of decorative and non-decorative florets: hortensia and lacecap (Uemachi and Nishio, 2005; Uemachi et al., 2006), and almost all of the hydrangea cultivars in the cut flower market have hortensia-type inflorescences.

Hortensia-type cut hydrangea flowers at two different harvest stages, fresh- and antique-stages, are marketed. Decorative sepals of hydrangea flowers develop blue or red coloring before the flowering and green and/or red colors after the flowering. Flowers cut at the fresh-stage are harvested just after the coloring of decorative sepals is completed before flowering, and those at the antique-

Received; October 31, 2015. Accepted; March 30, 2016.

First Published Online in J-STAGE on June 8, 2016.

* Corresponding author (E-mail: hyphy281@shinshu-u.ac.jp). stage are harvested after the development of green and/or red colors after flowering (Kitamura, 2013). Many cultivars show increased hydraulic conductance of stomata (stomatal conductance) in decorative sepals in the transition from the fresh to the antique-stage, and the extent varies by cultivar (Kitamura et al., 2014).

In several cultivars, necrotic spots appear on the decorative sepals in the course of the change from the fresh to the antique-stage, and their spread often results in necrosis of the whole decorative sepal (Fig. 1). This damage appears to be caused by pathogens and not by any nutrient disorder. The phyllosphere is a microbial habitat, and the surface of hydrangea plants is no exception (Hirano and Upper, 2000; Kitamura et al., 2008; Lindow and Brandl, 2003). Opened stomata are a major point of entry for plant pathogens (Huang, 1986), and the stomatal conductance-increase can provide them with a chance to invade decorative sepals at the antique-stage.

The increase in the stomatal conductance suggests that a transpiration increase occurs in antique-stage cut 


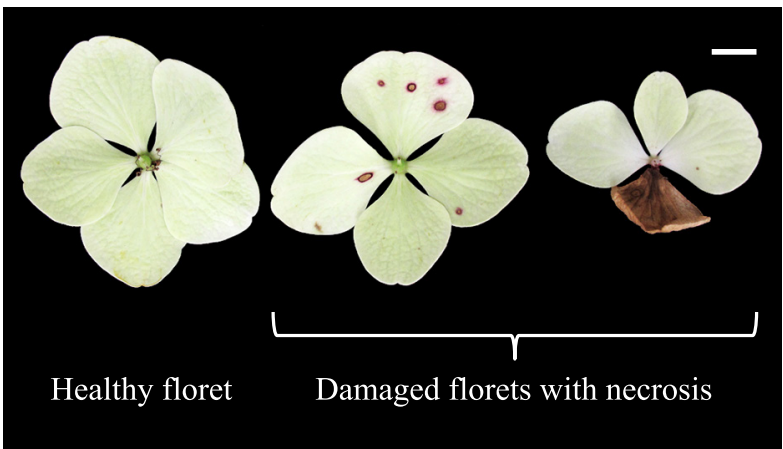

Fig. 1. Healthy and damaged antique-stage decorative florets. Spread of necrotic spots (center) causes necrosis of the whole decorative sepal (right). $B a r=1 \mathrm{~cm}$.

hydrangea flowers. In fresh-stage cut hydrangea flowers, defoliation, reducing the decorative florets, and covering the inflorescence are effective for extending the vase life, and it has been suggested that these treatments extend the vase life by suppressing transpirations from the cut flowers (Kitamura and Ueno, 2015; Mega, 1957). We hypothesized that the increase in the stomatal conductance can shorten the vase life of antiquestage cut hydrangea flowers. Abscisic acid (ABA) induces stomatal closure and reduces the water deficit in cut flowers (Kohl and Rundle, 1972; Livne and Vaadia, 1972). We accordingly attempted to close the stomata on the antique-stage decorative sepal by ABA treatment.

The aim of this study was to evaluate the effect of increased stomatal conductance of antique-stage decorative sepals on the severity of the necrosis appearing on the sepals and on the vase life of antique-stage cut hydrangea flowers.

\section{Materials and Methods}

\section{Plant materials}

Thirteen hydrangea cultivars ('Christmas', 'Endless Summer', 'Flambeau', 'Madame Emile Mouillere', 'Masja', 'No. 1', 'No. 2', 'No. 3', 'No. 4', 'No. 5', 'No. 6', 'Temari Ezo', and 'Xi'an') were used. Six cultivars used in this study were unidentified; 'No. 1', 'No. 3', and 'No. 5' originated as cuttings obtained from commercially available cut flowers, whereas 'No. 2', 'No. 4', and 'No. 6' originated from a garden shrub planted at Kyoto and Shinshu Universities. We will make available these unidentified cultivars to any researchers who wish to conduct confirmatory experiments. In the Shinshu University experimental farm, all plants were grown in 32.5-cm-diameter pots filled with $8 \mathrm{~L}$ of medium composed of $75 \%$ Metro Mix 250 (SunGro Horticulture Distribution, USA) and 25\% vermiculite (v/v) (Asahi Kogyo, Japan). The plants were grown from December 2013 to March 2014 in a greenhouse heated above $0^{\circ} \mathrm{C}$. Plants were grown under full sunlight from December 2013 to May 2014, under 70\% sunlight from June to July 2014, and under $50 \%$ sunlight from July to August 2014.

\section{Harvest and preparation of cut flowers}

From June to July 2014, the fresh-stage cut hydrangea flowers were harvested when approximately $80 \%$ of the decorative florets in the inflorescence developed the cultivar-specific coloration. From July to August 2014 and in August 2015, the antique-stage cut hydrangea flowers were harvested when approximately $80 \%$ of decorative florets in the inflorescence developed green and/or red coloring. Cut flowers were harvested with stems left approximately $60 \mathrm{~cm}$ long, and all leaves were immediately removed.

Damaged decorative florets with necrotic spots were pruned away just after harvest. Ends of cut flower stems were recut under distilled water just after harvest, leaving $50-\mathrm{cm}$ stems. All cut flowers were kept in plastic bottles filled with $1 \mathrm{~L}$ of distilled water. The bottle was loosely sealed with Parafilm (Pechiney Plastic Packaging Company, Chicago, USA) to suppress evaporation from the water surface. Cut flowers were placed in an environment-controlled room maintained at $25 \pm$ $2{ }^{\circ} \mathrm{C}$ and $50 \pm 5 \%$ relative humidity (RH) and under a 12 -h photoperiod at a light intensity of $10 \mu \mathrm{mol} \cdot \mathrm{m}^{-2} \cdot \mathrm{s}^{-1}$ provided by daylight fluorescent tubes (FL40SSN/37; Toshiba Lighting and Technology Co., Japan).

\section{Stomatal conductance of fresh- and antique-stage deco-} rative sepals

To achieve uniformity of the measurement environment, stomatal conductance of decorative sepals was measured in the above-mentioned environmentcontrolled room using a leaf porometer (SC-1; Decagon Devices, WA, USA). Measurements were performed under the light condition on the day after harvest. One decorative sepal was randomly chosen from five of each secondary inflorescence on the first and second nodes of the primary inflorescence axes, for a total of five decorative florets. The stomatal conductance was recorded at $1.5 \mathrm{~min}$ after the sensor head was clipped to the sepal. Measurements were performed with three randomly harvested cut flowers, and the average of 15 readings from 15 sepals was taken as the stomatal conductance of the cut flower. The 13 cultivars described above were measured. Significance of the correlation between stomatal conductance of fresh- and antiquestage decorative sepals was analyzed by Pearson's correlation coefficient.

\section{Damage to decorative sepals}

Using 5-7 additionally harvested antique-stage inflorescences for each cultivar, the severity of the necrosis appearing on decorative sepals was evaluated. Decorative florets showing necrosis on their sepals were counted as damaged florets (Fig. 1), and the percentage of damaged florets in each inflorescence was 
calculated. Percentages of damaged florets against the stomatal conductances of the decorative sepals were plotted for 13 cultivars, and the linear regression curve was fitted using Microsoft Excel software.

Stomatal closing treatment, diurnal changes in transpiration, vase lives of cut flowers, and weights of cut flowers

The effect of the stomatal conductance increase of the decorative sepal on the vase life of antique-stage cut hydrangea flowers was evaluated using 'No. 6', for which decorative sepals showed the highest increase in stomatal conductance among the cultivars. Stomatal closure was achieved by keeping cut flowers individually in plastic bottles filled with $10 \mathrm{mg} \cdot \mathrm{L}^{-1} \mathrm{ABA}$ (Sigma, St. Louis, USA) solution. Solutions of ABA were prepared as previously reported (Halevy et al., 1974). The solution was appropriately supplemented during the experiment. Control cut flowers were kept in distilled water. Four or five cut flowers were used for each treatment.

Nine to ten decorative sepals were randomly selected from each treatment on the day after harvest. At least one decorative sepal was chosen from each cut flower. Stomatal conductance was measured continually as described above, and the measurement was performed every morning until the first termination of vase life in each treatment. Even when the desiccation of selected decorative sepals progressed, the measurement was continued, but browning parts of decorative sepals were not measured.

On the day after harvest, the total mass of the bottle containing each cut flower and distilled water each under the control and ABA treatment conditions was recorded. The mass was recorded hourly, and the decrease in mass per hour was calculated as the transpiration rate per hour from the cut flower. The measurement was continued for three days.
The vase life ended when the sepal desiccation or browning became apparent on approximately $80 \%$ of decorative florets in any inflorescence. The sepal browning in cut flowers seems to be caused by some physiological disorder, and is clearly distinguished from the necrotic spots that occur in the transition from the fresh to the antique-stage before harvest. Decorative florets were counted after the end of vase life.

On the day after harvest, weights of the control and ABA-treated cut flowers were recorded. The weight was recorded in the same manner at the same time on the following day, and the relative weight of the cut flower for the first measurement was calculated. The measurements were continued for 4 days in the control and 9 days in the ABA treatment group.

\section{Results}

Correlation between stomatal conductance of freshand antique-stage decorative sepals

The stomatal conductance of 13 cultivars ranged from 3.8 to $8.4 \mathrm{mmol} \cdot \mathrm{m}^{-2} \cdot \mathrm{s}^{-1}$ at the fresh-stage (Fig. 2). At the antique-stage, it ranged from 5.2 to $29.8 \mathrm{mmol} \cdot \mathrm{m}^{-2} \cdot \mathrm{s}^{-1}$. There was a significant and high correlation between them $(r=0.845, P<0.001)$.

\section{Damage to decorative sepals and increase in stomatal conductance}

Percentages of damaged florets of 13 cultivars at harvest ranged from 4.9 to $48.8 \%$ (Fig. 3). The regression line indicated that the stomatal conductance of the antique-stage decorative sepals significantly regressed with the severity of the damage appearing on them $\left(R^{2}=0.819, P<0.05\right)$

ABA treatment lowered stomatal conductance and hourly transpiration of cut flowers in the light period

Stomatal conductance of ABA-treated cut flowers was lower than that of control cut flowers during the

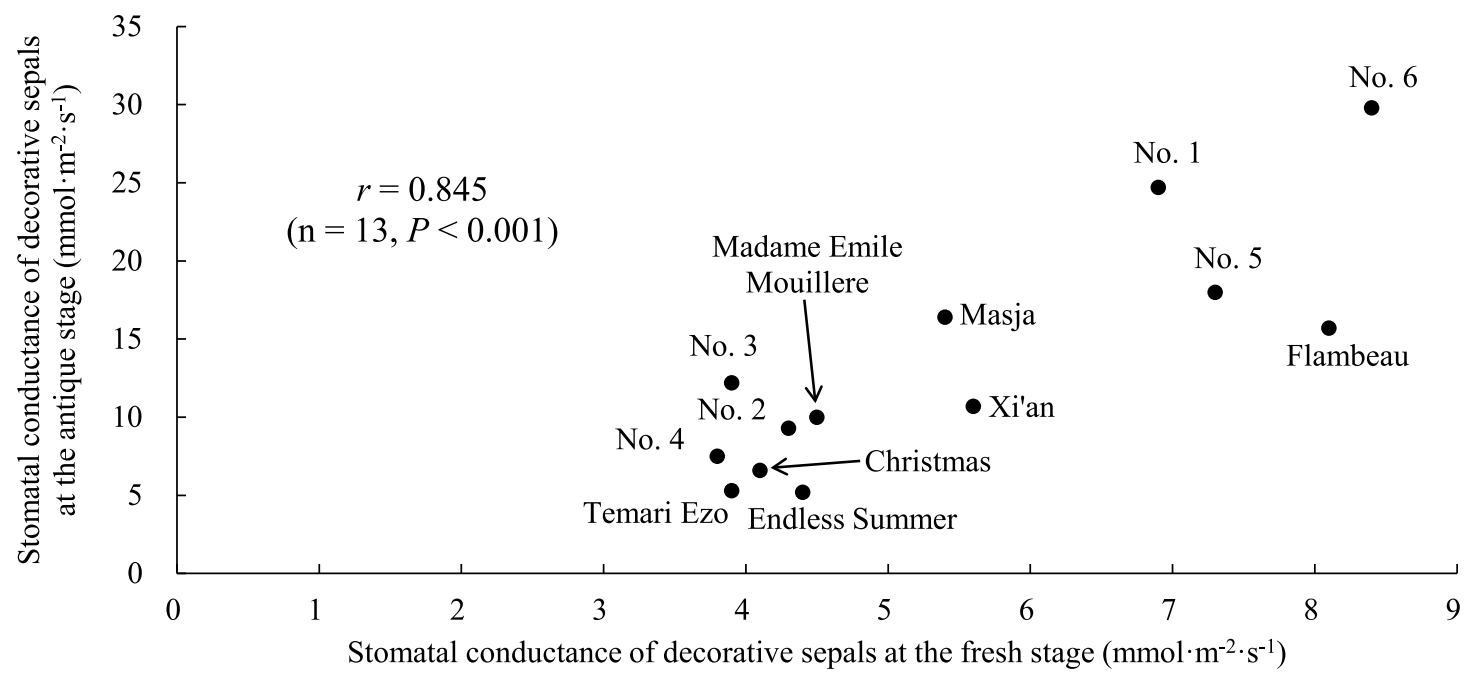

Fig. 2. Correlation between the stomatal conductance of decorative sepals at the fresh- and antique-stages. Data are means of 15 measurements. 
investigation (Fig. 4). In the first six days, stomatal conductance values of ABA-treated and control cut flowers were $5.2-7.2 \mathrm{mmol} \cdot \mathrm{m}^{-2} \cdot \mathrm{s}^{-1}$ and $18.7-28.1 \mathrm{mmol} \cdot \mathrm{m}^{-2} \cdot \mathrm{s}^{-1}$, respectively. Furthermore, in control cut flowers, stomatal conductance after day 6 decreased with time. No apparent diurnal change in transpiration was observed in ABA-treated cut flowers (Fig. 5). In contrast, transpiration of control cut flowers increased in the light periods.

$A B A$ treatment extended the vase life of antique-stage cut hydrangea flowers

Control and ABA-treated cut flowers had 203 and 252 decorative florets, respectively, and the difference was not significant (Table 1). The respective vase lives of these cut flowers were 12 and 18 days. Those of ABA-treated cut flowers were significantly longer than those of control cut flowers.
Weights of the cut flowers were maintained in ABAtreated antique-stage cut hydrangea flowers

Relative weights of the control cut flowers declined rapidly after the 3rd day (Fig. 6). In contrast, those of ABA-treated cut flowers were maintained until the sixth day and gradually declined after the seventh day.

\section{Discussion}

The present study suggested that many cultivars were susceptible to damage during the change from the fresh to antique-stage. Hydrangea leaf spot disease is caused by Corynespora cassiicola (Kasuyama and Idei, 1987), and the same fungus may cause necrosis on antiquestage decorative sepals. Opened stomata are a major point of entry for plant pathogens (Huang, 1986). In the present study, the stomatal conductance of antiquestage decorative sepals under field conditions was not measured. However, laboratory-measured stomatal con-

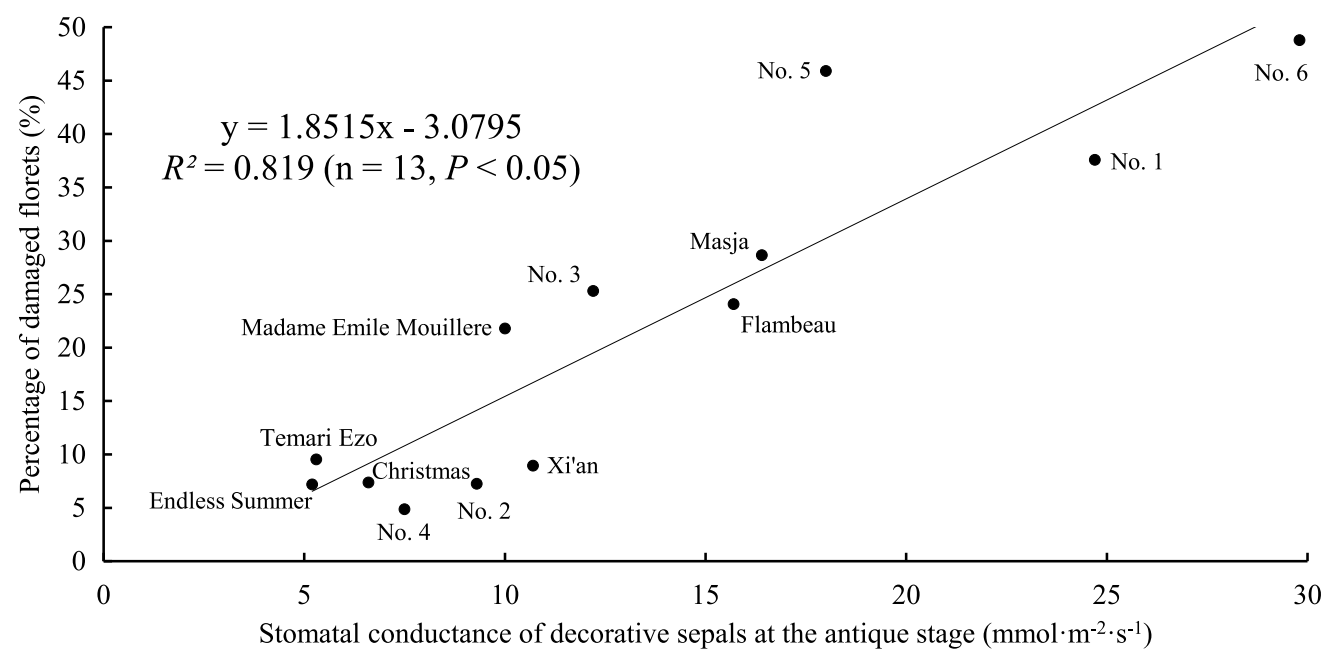

Fig. 3. Regression between stomatal conductance of decorative sepals at the antique-stage and the percentage of damaged florets. Florets with necroses that occured in the transition from the fresh to the antique-stage before harvest were counted as damaged florets. Data are means of 15 (stomatal conductance) or 5-7 (percentage of damaged florets) measurements.

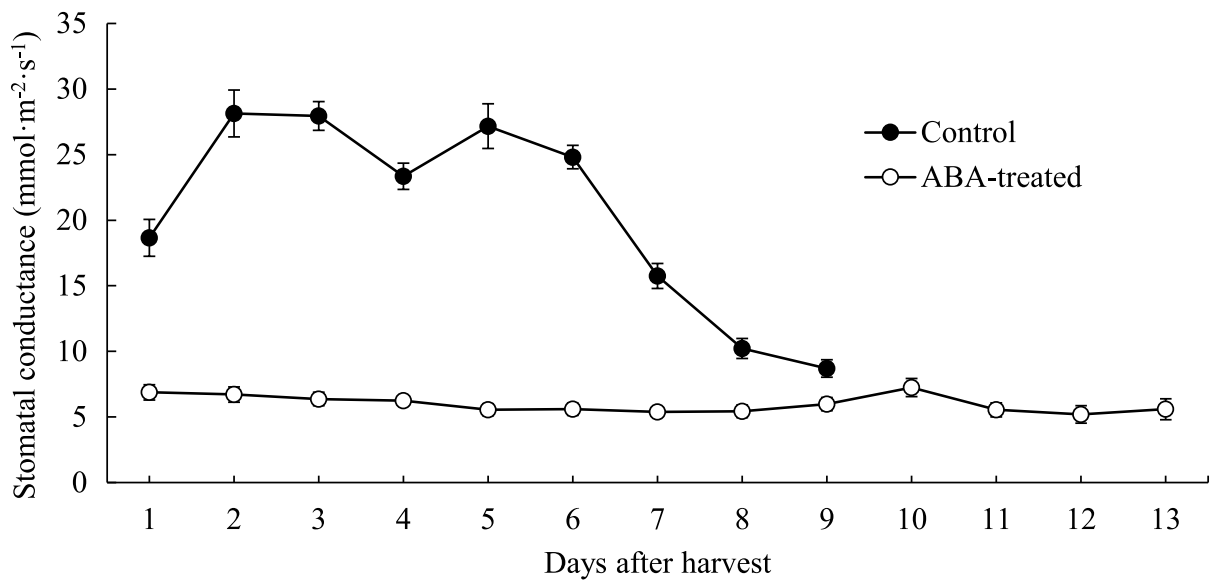

Fig. 4. Changes in stomatal conductance of decorative sepals of the control and ABA-treated cut flowers cut at the antique-stage. Measurements were terminated on days 9 (control) and 13 (ABA treatment) due to the end of vase lives in some cut flowers in each treatment. Values are the means \pm SE $(n=9-10)$. 


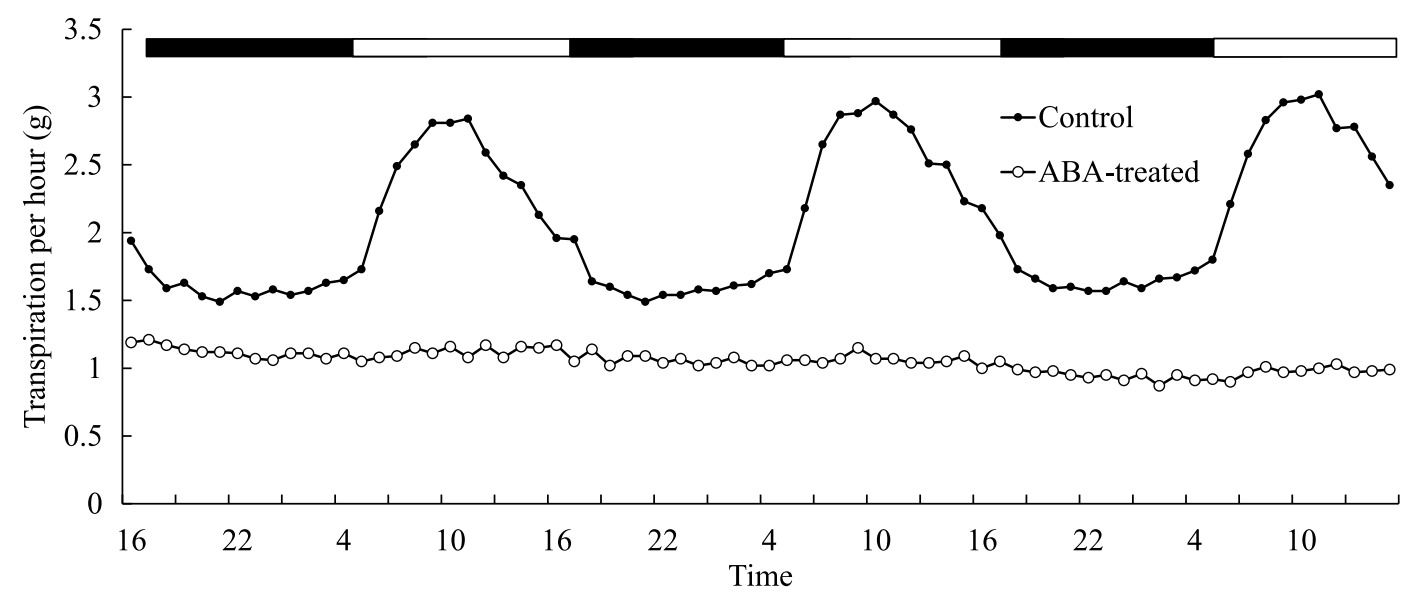

Fig. 5. Diurnal changes in the transpiration from the control and ABA-treated antique-stage cut flowers under the 12-h photoperiods. $\bullet$, Control cut flowers; $\bigcirc$, ABA-treated cut flowers. The transpiration of one cut flower each under the control and ABA treatment was measured hourly. Bars on the figure indicate the light (open bar) and dark (closed bar) periods.

Table 1. Number of decorative florets and the vase life of control and ABA-treated antique-stage cut flowers.

\begin{tabular}{|c|c|c|c|c|}
\hline \multirow{2}{*}{ Treatment } & \multirow{2}{*}{$\begin{array}{c}\text { Number of } \\
\text { decorative florets }\end{array}$} & \multirow{2}{*}{ Vase life (day) } & \multicolumn{2}{|c|}{ End of vase life ${ }^{z}$} \\
\hline & & & Browning & Desiccation \\
\hline Control & $203 \pm 19^{y}$ & $12 \pm 2$ & 2 & 2 \\
\hline ABA-treated & $252 \pm 14$ & $18 \pm 2$ & 2 & 3 \\
\hline Analysis of $t$-test ${ }^{\mathrm{x}}$ & NS & $*$ & - & - \\
\hline
\end{tabular}

${ }^{z}$ Number of cut flowers. Vase life was terminated when sepal browning or sepal desiccation became apparent on approximately $80 \%$ of decorative florets in an inflorescence.

$\mathrm{y}$ The values are the mean $\pm \mathrm{SE}(\mathrm{n}=4-5)$.

${ }^{x}$ NS and * indicate non-significant and significant at $P<0.05$.

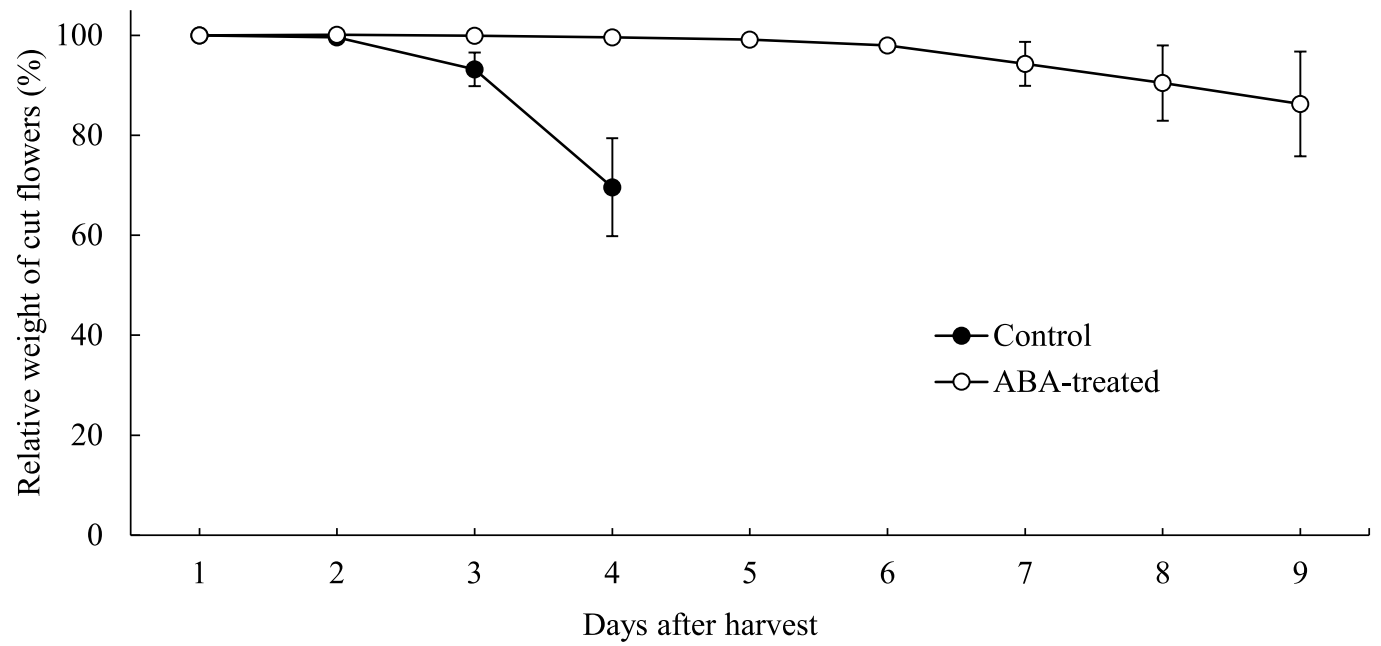

Fig. 6. Changes in the relative weights of the control and ABA-treated cut flowers. $\bullet$, Control cut flowers; $\circ$, ABA-treated cut flowers. Weights of the cut flowers were measured daily, and relative weights for the first measurement were calculated. Values are the means $\pm \operatorname{SE}(n=4)$.

ductance regressed in terms of the percentages of damaged florets. Stomatal conductance-increasing cultivars may also show higher stomatal conductance in the field and provide C. cassiicola a greater chance than nonincreasing cultivars to invade decorative sepals through their open stomata at the antique-stage. Necrotic damage is a major factor spoiling the quality of antique- stage cut hydrangea flowers, and based on our observation and personal communications with market staff, $10 \%$ or less of damaged florets relative to the total number of decorative florets is acceptable for cut flower sales. However, no effective technique for suppressing the emergence of damage has been proposed. The introduction of stomatal conductance non-increasing culti- 
vars would be a major aid in the damage-suppressive antique-stage cut hydrangea flower production, and the same would be true for antique-stage pot hydrangea production.

Changes in the relative weight of the control antiquestage cut hydrangea flowers indicates that the increase in the stomatal conductance caused a rapid loss of water balance in the decorative sepals. Although the underlying mechanism remains unknown, the loss of water balance results in the desiccation or browning of decorative sepals and end of vase life. ABA treatment suppressed the transpiration from the antique-stage cut hydrangea flowers in the light period. ABA treatment extended the vase life of the antique-stage cut hydrangea flowers. ABA accelerates senescence of the plant tissue including the floral organ (Addicott and Lyon, 1969; Arditti et al., 1971; Mayak and Halevy, 1972). Suppression of transpiration would be effective enough to compensate for the negative effect of ABA on their vase lives. Therefore, the suppression of the transpiration from antique-stage decorative sepals was effective to extend the vase lives of cut hydrangea flowers. This finding suggests the inadequacy of stomatal conductance-increasing cultivars for antique-stage cut hydrangea production from another perspective.

In this study, the ABA responsiveness of stomata on antique-stage decorative sepals was confirmed. Low stomatal conductance observed in ABA-treated antiquestage decorative sepals indicated the successful reduction of stomatal conductance over the postharvest period. The decrease in stomatal conductance observed after the sixth day in control cut flowers is likely due to the reduced water absorption by cut flowers and consequent stomatal closure. Halevy et al. (1974) reported that ABA treatment induces stomatal closure in leaves of cut rose flowers. Hew et al. (1980) suggested that the stomata on the tepal of some orchids were nonresponsive to $\mathrm{ABA}$ treatment. In hydrangeas, stomata on fresh-stage decorative sepals were almost closed (Kitamura and Ueno, 2015). The present study also suggested that the acquisition of stomatal functionality in antique-stage cut hydrangea flowers accelerated stomatal opening in the light period resulting in water loss. Light stimulates stomatal opening (Roelfsema and Hedrich, 2005). Studies of the water uptake rate of cut rose flowers with leaves in light and dark periods have suggested that the water uptake rate was higher in the light period (Carpenter and Rasmussen, 1973; Doi et al., 1999). Doi et al. (1999) also reported that a transpiration increase occurred even under light from fluorescent lamps such as those used in the present study. Increases in water uptake observed in these two studies were due to leaf stomatal opening. The ABA responsiveness and photoperiodic change in the transpiration observed in the present study suggest a similarity in the function of stomata in antique-stage decorative sepals to those in leaves.
An increase in the stomatal conductance in antiquestage decorative sepals could affect, in several different ways, the emergence of damage on decorative sepals and on the vase life of cut flowers. Notably, some cultivars bred for cut flower production show a stomatal conductance increase in decorative sepals at the antique-stage (Kitamura et al., 2014), and such cultivars would be unsuitable for antique-stage cut hydrangea flower production. Because farmers producing antiquestage cut hydrangea flowers use the same cultivars for fresh-stage cut flower production, screening for stomatal conductance non-increasing cultivars should be conducted for the production of both fresh- and antiquestage cut hydrangea flowers.

An increase in the stomatal conductance may also be detected as a lower decorative sepal temperature. Some Arabidopsis thaliana ABA signal transduction mutants have been isolated on the basis of leaf temperature using infrared thermal imaging (Merlot et al., 2002; Wang et al., 2004). Thermal image acquisition is time saving, and an infrared camera is less expensive than a leaf porometer.

The stomatal conductance of antique-stage decorative sepals can be used as an index in screening for stomatal conductance non-increasing genotypes. However, its use requires breeders to wait until the seedlings develop antique-stage decorative sepals. The present results indicated that the stomatal conductance of antiquestage decorative sepals highly correlate with those of fresh-stage decorative sepals. Several weeks are needed for the transition from the fresh to the antique-stage. The fresh-stage decorative sepal-based screening would shorten the breeding period.

Further studies, such as to investigate the appropriate test conditions for stomatal conductance-based screening, and/or inheritance of a stomatal conductance nonincreasing-phenotype are needed to achieve highly efficient breeding of hydrangea cultivars for cut flower production.

\section{Literature Cited}

Addicott, F. R. and J. L. Lyon. 1969. Physiology of abscisic acid and related substances. Ann. Rev. Plant. Physiol. 20: 139164.

Arditti, J., B. Flick and D. Jeffrey. 1971. Post-pollination phenomena in orchid flowers. New Phytol. 70: 333-341.

Carpenter, W. J. and H. P. Rasmussen. 1973. Water uptake rates by cut roses (Rosa hybrida) in light and dark. J. Amer. Soc. Hort. Sci. 98: 309-313.

Doi, M., M. Miyagawa-Namao, K. Inamoto and H. Imanishi. 1999. Rhythmic changes in water uptake, transpiration and water potential of cut roses as affected by photoperiods. J. Japan. Soc. Hort. Sci. 68: 861-867 (In Japanese with English abstract).

Halevy, A. H., S. Mayak, T. Tirosh, H. Spiegelstein and A. M. Kofranek. 1974. Opposing effects of abscisic acid on senescence of rose flowers. Plant Cell Physiol. 15: 813-821.

Hew, C. S., G. L. Lee and S. C. Wong. 1980. Occurrence of nonfunctional stomata in the flowers of tropical orchids. Ann. 
Bot. 46: 195-201.

Hirano, S. S. and C. D. Upper. 2000. Bacteria in the leaf ecosystem with emphasis on Pseudomonas syringae - a pathogen, ice nucleus, and epiphyte. Microbiol. Mol. Biol. Rev. 64: 624-653.

Huang, J. S. 1986. Ultrastructure of bacterial penetration in plants. Ann. Rev. Phytopathol. 24: 141-157.

Kasuyama, S. and T. Idei. 1987. Hydrangea leaf spot disease and Gentiana scabra leaf spot disease observed in Okayama Prefecture. Ann. Phytopath. Soc. Japan. 53: 377 (In Japanese).

Kitamura, Y. 2013. Production of cut hydrangea flower. p. 7-14. In: Nosangyosonbunkakyoukai (ed.). Resent Techniques in Floriculture. Series 5. (In Japanese). Nousangyosonbunkakyoukai, Tokyo.

Kitamura, Y. and S. Ueno. 2015. Inhibition of transpiration from the inflorescence extends the vase life of cut hydrangea flowers. Hort. J. 84: 156-160.

Kitamura, Y., M. Hosokawa, C. Tanaka and S. Yazawa. 2008. Identification and sterilization of epiphytic bacterial flora near hydrangea shoot apical meristems. J. Japan. Soc. Hort. Sci. 77: 418-425.

Kitamura, Y., S. Ueno, T. Watanabe and H. Aizawa. 2014. Comparison of vase life of cut flower and stomatal conductance of sepals between autumn and fresh cut hydrangea flower. Hort. Res. (Japan) 13 (Suppl. 2): 526 (In Japanese).

Kohl, H. C. and D. L. Rundle. 1972. Dcreasing water loss of cut roses with abscisic acid. HortScience 7: 249.

Lindow, S. E. and M. T. Brandl. 2003. Microbiology of the phyllosphere. Appl. Env. Microbiol. 69: 1875-1883.
Livne, A. and Y. Vaadia. 1972. Water deficits and hormone relations. p. 255-276. In: T. T. Kozlowski (ed.). Water Deficits and Plant Growth. Academic Press, New York.

Mayak, S. and A. H. Halevy. 1972. Interelationships of ethylene and abscisic acid in the control of rose petal senescence. Plant Physiol. 50: 341-346.

Mega, K. 1957. Water absorption and transpiration of cut flowers. Bull. Univ. Osaka Pref. 7: 15-22.

Merlot, S., A. C. Mustilli, B. Genty, H. North, V. Lefebvre, B. Sotta, A. Vavasseur and J. Giraudat. 2002. Use of infrared thermal imaging to isolate Arabidopsis mutants defective in stomatal reguration. Plant J. 30: 601-609.

Roelfsema, M. R. G. and R. Hedrich. 2005. In the light of stomatal opening: new insights into 'the watergate'. New Phytol. 167: 665-691.

Uemachi, T. and T. Nishio. 2005. Relationship between the inflorescence structure and setting of decorative flowers on lacecap cultivars of Hydrangea macrophylla (Thunb.) Ser. and H. serrata (Thunb.) Ser. Hort. Res. (Japan) 4: 435-438 (In Japanese with English abstract).

Uemachi, T., M. Kurokawa and T. Nishio. 2006. Comparison of inflorescence composition and development in the lacecap and its sport, hortensia Hydrangea macrophylla (Thunb.) ser. J. Japan. Soc. Hort. Sci. 75: 154-160.

Wang, Y., G. Holoroyd, A. M. Hetherington and C. K-Y. Ng. 2004. Seeing 'cool' and 'hot'-infrared thermography as a tool for non-invasive, high-throughput screening of Arabidopsis guard cell signaling mutants. J. Exp. Bot. 55: 1187-1193. 